American Journal of Applied Sciences 8 (12): 1241-1248, 2011

ISSN 1546-9239

(C) 2011 Science Publications

\title{
Ginger Supplementation Enhances Working Memory of the Post-Menopause Women
}

\author{
${ }^{1}$ Naritsara Saenghong, ${ }^{2,3}$ Jintanaporn Wattanathorn, \\ ${ }^{2,3}$ Terdthai Tong-Un, ${ }^{2,3}$ Supaporn Muchimapura, \\ ${ }^{4}$ Nawanant Piyavhatkul, ${ }^{5}$ Chuleratana Bunchonglikitkul \\ and ${ }^{5}$ Tanwarat Kajsongkram \\ ${ }^{1}$ Department of Physiology, (Neuroscience Program) and Graduate School, \\ Faculty of Medicine, Khon Kaen University, 40002, Thailand \\ ${ }^{2}$ Department of Physiology, Faculty of Medicine, \\ ${ }^{3}$ Integrative Complimentary Alternative Medicine Research Group, \\ ${ }^{4}$ Department of Psychiatry, Faculty of Medicine, \\ Khon Kaen University, 40002, Thailand \\ ${ }^{5}$ Thailand Institute of Scientific and Technological Research, \\ Pathumthani, 12120, Thailand
}

\begin{abstract}
Problem statement: Cognitive impairment is one important problem in post-menopausal women. Although hormone therapy can improve this condition, it also produces adverse effect. Recent findings showed that this condition could be mitigated by the herb. Ginger or Zingiber officinale Roscoe, a plant in a family of Zingiberaceae, was previously demonstrated the neuroprotection and cognitive enhancing effects. Therefore, this study was set up to determine whether ginger rhizome extract could improve attention and working memory of the postmenopausal women. Approach: Sixty healthy post-menopausal women were randomly assigned to receive either placebo or standardized plant extract at doses of 400 and $800 \mathrm{mg}$ once daily for 3 months. After the assessment of biographic information, they were evaluated the working memory and cognitive function using computerized battery test and the auditory oddball paradigm of event related potential before and after 3-month of intervention. Results: The ginger treated group decreased N100 and P300 latencies but increased N100 and P300 amplitudes in accompany with the enhanced working memory including the power of attention, continuity of attention, speed and quality of memory. Conclusion: Our results suggested that ginger is the potential cognitive enhancer for post-menopausal women. However, further researches are still required.
\end{abstract}

Key words: Ginger rhizome, Zingiber officinale, attention impairment, working memory, postmenopausal women, computerized battery, ginger extract, intellectual function

\section{INTRODUCTION}

Episodic memory decline and attention impairment are recognized as the important disturbances commonly found in post-menopausal period and normal aging (Weber and Mapstone, 2009; Perfect and Maylor, 2000; Halbreich et al., 1995). Several lines of evidence demonstrated that cognition declined progressively over the menopause, with significant diminution processing speed and working memory (Greendale et al., 2010;
Schaafsma et al., 2010). Recent findings showed that this condition could be improved by Hormone Replacement Therapy (HRT) (Khoo et al., 2010; Sherwin, 2005; Rocca et al., 2010). However, numerous adverse effects were reported (Anderson et al., 2003; Beral, 2003; Beral et al., 2007; Calle et al., 2009; Rugg and Coles, 1995; Hildebrand et al., 2010; Daniel and Bohacek, 2010). Due to the limitation of therapeutic efficacy, many post-menopause women preferred using Complementary and Alternative

Corresponding Authors:Jintanaporn Wattanathorn, Department of Physiology, Faculty of Medicine, Khon Kaen University, Khon Kaen, 40002, Thailand Tel: +66-43-348394 Fax: +66-43-348394 
Medicine (CAM) therapies (Borrelli and Ernst, 2010). Herbal medicine and dietary supplements is the most commonly used strategies among various alternative strategies (Low, 2005; Kronenberg and Fughh-Berman, 2002; Wattanathorn et al., 2008a; 2008b; Tong-Un et al., 2010). Ginger or Zingiber officinale is belonging to Zingiberacae family. It has been long-term used as both spicy and medicine in Asian, Indian and Arabian folklore. The rhizome of $Z$. officinale exhibits a wide range of pharmacological properties including antilipidemia (Verma and Bordia, 2001), anti-emetic (Langner et al., 1998), anti-inflammation and antiarthritis (Srivastava and Mustafa, 1992). In Ayuraveda, Traditional Chinese Medicine and Arabic Medicine, ginger has been reported to use for managing memory impairment either as ginger extract, ginger tea or as ingredient in food formulations and preparation (Keith, 2006). Recently, it was found that ginger could suppress acetylcholineasterase (Oboh et al., 2010) and improved memory impairment in animal model of stroke (Watthanatorn et al., 2011). Although ginger has been long-term used in traditional folklore to enhance memory, less clinical evidence is available until now. Therefore, the present study was carried out to determine the effect of ginger extract on working memory and attention in postmenopausal women.

\section{MATERIAL AND METHODS}

Participants: Sixty healthy Thai middle aged women (mean age 53.40 \pm 3.57 years) were recruited to participate in this project, which was approved by the Ethical Committee of Faculty of Medicine, Khon Kaen University. Prior to the investigation, each volunteer must sign an inform consent form, completed the medical healthcare questionnaire and the participants must also be screened for physical health by the physician in order to assure the health condition. Inclusion criteria are included healthy, middle-aged women between the ages of 50 and 60 , who has experienced at least twelve consecutive months of amenorrhea. Exclusion criteria included any history of cardiovascular diseases, respiratory diseases, neuropsychological diseases, head injury, diabetes, cancer, alcohol addiction, smokers of more than 10 pieces per day. Any persons taking prescribed and nonprescribed drugs or nutraceutical compounds influencing the function of the nervous system were excluded. The study target was not elderly postmenopausal women. We also excluded very young and oophorectomized woman whom a fall in hormones could have more intense effect. The participants were randomly divided into 3 separated groups including placebo, Zingiber officinale 400 and 800 respectively.

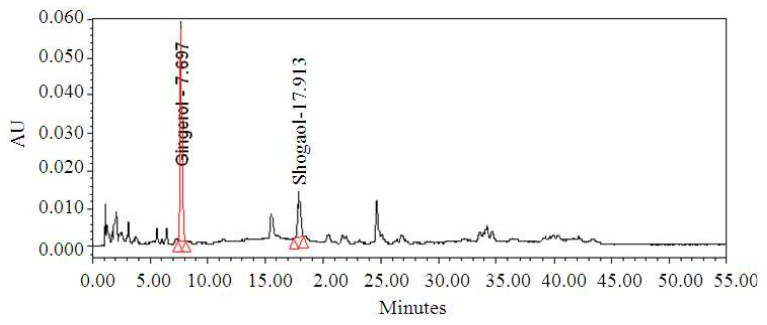

Fig. 1: HPLC Chromatogram (high performance liquid chromatography) of Zinigber officinale extract. Column: Luna $\mathrm{C}_{18} 4.6 \times 150 \mathrm{~mm}$. Mobile phase: water/acetronitrile (gradeint)

The preparation of the standardized extract of Zingiber officinale: A standardized extract of Zingiber officinale was prepared by the Thailand Institute of Scientific and Technological Research in Pathumthani, Thailand. Standardization and conformity of the extract were assured by strict in-process controls during manufacture and complete analytical control of the resulting dry extract. In brief, the dried ginger rhizome powder was extracted with $95 \%$ ethanol in a stainless steel tank for 5-10 days. The filtrate was evaporated to dryness under a vacuum at $35^{\circ} \mathrm{C}$ on a rotary evaporator. The production yield of the extract was $6.84 \% \mathrm{w} / \mathrm{w}$. The phenolic compound of standardized ginger extract contained $7.33 \% \mathrm{w} / \mathrm{w}$ of 6-gingerol and $1.34 \% \mathrm{w} / \mathrm{w}$ of $6-$ shogaol. Zingiber officinale was analyzed by HPLC (high performance liquid chromatography) as shown on Fig. 1. This fingerprint has been prepared by Mrs. Tanwarat Kajsongkram, Thailand Institute of Scientific and Technological Research (TISTR), Pathumthani, Thailand

Procedures and treatments: This study was conducted as a 3 month, double-blind, placebo-controlled and randomized trial. A random list of numbers was generated by computer. After being randomly assigned to various treated groups, each participant received one capsule of either placebo or ginger extract at various doses ranging from 400 and $800 \mathrm{mg}$ once daily. The placebo and ginger capsules had the same color, texture, size and odor. All participants were screened for their baseline intellectual function using Standard Progressive Matrices (SPM) in order to avoid confounding error induced by the intellectual function problem. Then, they were assessed the cognitive processing ability and working memory after 3 months of treatment.

ERP recording: All subjects were assessed for cognitive performance using the classic "oddball paradigm" of auditory event-related potentials (N100 and P300 amplitudes and latencies) (Kennedy et al., 2003). The Electroencephalogram (EEG) was recorded 
via $\mathrm{Cz}$ and linked mastoids were used as reference for the electrode. The resistance of the electrodes was kept below $5 \mathrm{kohm}$. The analog filter band pass was 1-100 $\mathrm{Hz}$ (Drake et al., 1989). For each stimulus, an epoch of 500-ms duration including a 100-ms pre-stimulus period was extracted from the continuous EEG. Epochs with a voltage change below $0.1 \mu \mathrm{V}$ or above $70 \mu \mathrm{V}$ were rejected from further analysis.

ERP measurement: The subjects listened to a train of tone bursts presented binaurally through headphones. The standard stimuli had a tonal frequency of $650 \mathrm{~Hz}(60$ $\mathrm{dB}, 200 \mathrm{~ms}$ ) and occurred with a tonal frequency of $80 \%$. The target stimuli had a tonal frequency of $1 \mathrm{kHz}(60 \mathrm{~dB}$, $200 \mathrm{~ms}$ ) and occurred with a probability of $20 \%$. All participants were informed to pay attention and mentally count infrequent target tones. Inter-stimulus intervals varied randomly between 1250 and $3000 \mathrm{~ms}$. The N100 latency range was determined to be $65-135 \mathrm{~ms}$ and the P300 latency range was determined to be $280-375 \mathrm{~ms}$. Both the latency and maximum amplitudes were measured for N100 and P300 deflections. Any peaks outside of this range were measured manually and all peaks were visually examined prior to measurement.

Computerized assessment battery test: The computerized assessment battery test was modified from the CDR computerized assessment battery test used in hundreds of European and North American drug trials. It is sensitive to acute cognitive improvements as well as impairments with a wide variety of substances (Moss et al., 1998; Wesnes, 2001). Presentation was performed using notebook computers with a highresolution VGA colour monitor and, with the exception of written word recall tests, all responses were recorded via a two-button (yes/no) response box. The entire selection of tasks took approximately $20 \mathrm{~min}$. Tests were administered in the following order: word presentation, picture presentation, simple reaction time, digit vigilance task, choice reaction time, spatial working memory, numeric working memory, delayed word recognition and delayed picture recognition.

Word presentation: Fifteen words, matched for frequency and concreteness, were presented in sequence on the monitor for the participant to remember. The stimulus duration was $1 \mathrm{~s}$, as was the inter-stimulus interval.

Picture presentation: A series of 20 photographic images was presented on the monitor at the rate of 1 every $3 \mathrm{~s}$, with stimulus duration of $1 \mathrm{~s}$, for the participant to remember.
Simple reaction time: The participant was instructed to press the 'yes' response button as quickly as possible every time the word 'yes' was presented on the monitor. Fifty stimuli were presented with an interstimulus interval that varied randomly between 1 and $3.5 \mathrm{~s}$. Reaction times were recorded in milliseconds.

Digit vigilance task: A target digit was randomly selected and constantly displayed to the right of the monitor screen. A series of digits was presented in the centre of the screen at the rate of $80 / \mathrm{min}$ and the participant was required to press the 'yes' button as quickly as possible every time the digit in the series matched the target digit. The task lasted $1 \mathrm{~min}$ and there were 15 stimulus-target matches. Task measures were accuracy $(\%)$, reaction time (milliseconds) and false alarms.

Choice reaction time: Either the word 'no' or the word 'yes' was presented on the monitor and the participant was required to press the corresponding button as quickly as possible. There were 50 trials of which the stimulus word was chosen randomly with equal probability, with a randomly varying inter-stimulus interval between 1 and $3.5 \mathrm{~s}$. Reaction times (millisecond) and accuracy (\%) were recorded.

Spatial working memory: A pictorial representation of a house was presented on the screen with four of its nine windows lit. The participant was instructed to memorize the position of the illuminated windows. In 36 subsequent presentations of the house, one of the windows was illuminated and the participant decided whether or not this matched one of the lighted windows in the original presentation. The participant made their response by pressing the 'yes' or 'no' response button as quickly as possible. Mean reaction times were measured in milliseconds and the accuracy of responses to both original and novel (distractor) stimuli were recorded as percentages used to derive a 'percentage greater than chance performance' score.

Numeric working memory: Five digits were presented sequentially for the participant to hold in memory. This was followed by a series of 30 probe digits for each of which the participant decided whether or not it had been in the original series and pressed the 'yes' or 'no' response button as appropriate and as quickly as possible. This was repeated two further times with different stimuli and probe digits. Mean reaction times were measured in milliseconds and the accuracy of responses to both original and novel (distractor) stimuli were recorded as percentages that were used to derive a 'percentage greater than chance performance' score. 
Delayed word recognition: The original words and 15 distractor words were presented one-at-a-time in randomized order. For each word, the participant indicated whether or not she recognized it as being included in the original list of words by pressing the 'yes' or 'no' button as appropriate and as quickly as possible. Mean reaction times were measured in milliseconds and the accuracy of responses to both original and novel (distractor) stimuli were recorded as percentages that were used to derive a 'percentage greater than chance performance' score.

Delayed picture recognition: The original pictures and 20 distractor pictures were presented one-at-a-time in a randomized order. For each picture, participants indicated whether or not it was recognized as being from the original series by pressing the 'yes' or 'no' button as appropriate and as quickly as possible. Mean reaction times were measured in milliseconds and the accuracy of responses to both original and novel (distractor) stimuli were recorded as percentages that were used to derive a 'percentage greater than chance performance' score.

Statistical analysis: Comparison between doses was made using Analysis of Variance (ANOVA) and followed the recommendations of Keppel and Wickens (2004), with planned comparison being made between the placebo and each of the two active treatments utilizing t tests. Statistical significance was regarded at p-value $<0.05$

\section{RESULTS}

Demographic data of subjects: The baseline data about characteristic of subjects in all groups were shown in Table 1. No significant difference of all parameters among various groups was observed.

Effect of Zingiber officinale on event-related potential components (ERP): The effects of Zingiber officinale on ERP components were shown in Table 2 and Fig. 2. The pre-dose baseline data of latency and amplitude of both N100 and P300 of various groups showed no significant difference $[\mathrm{f}(2,57)=0.3765, \mathrm{p}=$ $0.6879 ; \mathrm{f}(2,57)=0.1865, \mathrm{p}=0.8303 ; \mathrm{f}(2,57)=0.0408$, $\mathrm{p}=0.9600$ and $\mathrm{f}(2,57)=0.0138, \mathrm{p}=0.9863$, respectively]. It was found that when the treatment was prolonged further to 3 months, the subjects who received Zingiber officinale at doses of 400 and $800 \mathrm{mg}$ showed the enhanced amplitudes of both $\mathrm{N} 100(\mathrm{t}=$ 3.6444, $\mathrm{p}=0.0004 ; \mathrm{t}=4.1137, \mathrm{p}=0.0001)$ and $\mathrm{P} 300(\mathrm{t}$ $=2.1654, \mathrm{p}=0.0183 ; \mathrm{t}=3.2504, \mathrm{p}=0.0012)$ respectively compared to placebo treated group.

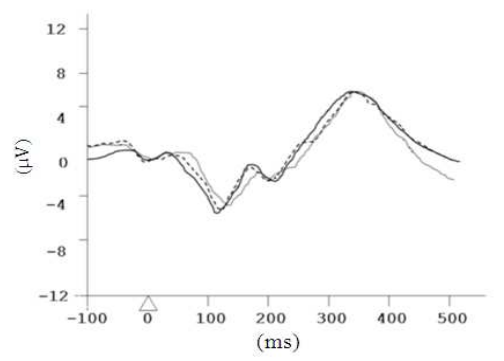

(a)

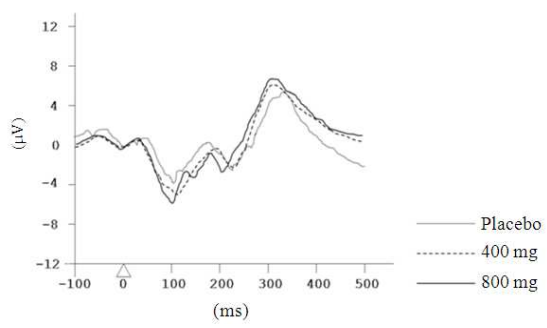

(b)

Fig. 2: Average waveforms of the auditory event related potential at electrode $\mathrm{Cz}$ at various periods of treatment; (a) Pre-dose baseline, (b) 3rd month after substance administration

Table 1: Demographic data of subjects

\begin{tabular}{lccc}
\hline Baseline data & \multicolumn{1}{c}{ Placebo } & \multicolumn{1}{c}{$400 \mathrm{mg}$} & \multicolumn{1}{c}{$800 \mathrm{mg}$} \\
\hline Age (years) & $53.92 \pm 3.82$ & $54.33 \pm 4.12$ & $54.33 \pm 3.17$ \\
Education (years) & $5.50 \pm 3.70$ & $5.40 \pm 3.68$ & $5.15 \pm 2.74$ \\
$\begin{array}{l}\text { Full scale IQ } \\
\text { Blood sugar }\end{array}$ & $98.95 \pm 4.42$ & $99.75 \pm 4.23$ & $98.85 \pm 6.01$ \\
$\begin{array}{l}\text { Body mass index } \\
\text { Systolic blood } \\
\text { pressure (mmHg) }\end{array}$ & $21.95 \pm 1.90$ & $22.78 \pm 2.06$ & $23.12 \pm 1.83$ \\
$\begin{array}{l}\text { Diastolic blood } \\
\text { pressure (mmHg) }\end{array}$ & $121.00 \pm 7.72$ & $117 . \pm 8.49$ & $117.85 \pm 9.76$ \\
$\begin{array}{l}\text { Menstrual } \\
\text { cessation (years) }\end{array}$ & $82.25 \pm 2.53$ & $82.80 \pm 2.73$ & $80.50 \pm 3.73$ \\
$\begin{array}{l}\text { Data were presented as mean } \pm \text { SD. f and p-value were compared } \\
\text { between groups (n }=20 / \text { group) }\end{array}$ & &
\end{tabular}

Table 2: Effect of Zingiber officinale on event-related potential

\begin{tabular}{llll}
\hline Wave & Pre-dose baseline score & Post-dose score 3 month \\
\hline N100 latency & Placebo & $116.80 \pm 1.385$ & $112.50 \pm 8.26$ \\
& $400 \mathrm{mg}$ & $114.35 \pm 11.44$ & $108.45 \pm 10.06$ \\
& $800 \mathrm{mg}$ & $114.05 \pm 8.31$ & $102.75 \pm 9.83^{* * *}$ \\
N100 amplitude & Placebo & $5.70 \pm 10.08$ & $5.50 \pm 1$ \\
& $400 \mathrm{mg}$ & $5.90 \pm 1.37$ & $6.70 \pm 1.03^{* * *}$ \\
& $800 \mathrm{mg}$ & $5.75 \pm 1.29$ & $7.05 \pm 1.31^{* * *}$ \\
P300 latency & Placebo & $332.70 \pm 12.96$ & $331.50 \pm 15.58$ \\
& $400 \mathrm{mg}$ & $332.25 \pm 13.81$ & $319.95 \pm 15.29^{*}$ \\
P300 amplitude & $800 \mathrm{mg}$ & $332.90 \pm 10.20$ & $315.30 \pm 11.26^{* * *}$ \\
& Placebo & $7.25 \pm 1.10$ & $7.15 \pm 1.20$ \\
& $400 \mathrm{mg}$ & $7.25 \pm 1.01$ & $8.00 \pm 1.21^{*}$ \\
& $800 \mathrm{mg}$ & $7.20 \pm 1.10$ & $8.50 \pm 1.35^{* *}$ \\
\hline
\end{tabular}

The amplitudes and latencies of event-related potential elicited by oddball paradigm at $\mathrm{Cz}$ electrode were measured. Data are presented as mean $\pm \mathrm{SD}(\mathrm{n}=20 /$ group $) . *, * *, * * *=\mathrm{P}$-value $<0.05,0.01$ and 0.001 compare to placebo treated group respectively 
Am. J. Applied Sci., 8 (12): 1241-1248, 2011

Table 3: Effect of Zingiber officinale on working memory assessing via computerized battery test

\begin{tabular}{|c|c|c|c|}
\hline \multirow{2}{*}{$\begin{array}{l}\text { Measurement } \\
1 . \text { Word }\end{array}$} & \multicolumn{2}{|c|}{ Pre-dose baseline score } & \multirow{2}{*}{$\begin{array}{l}\text { Post-dose } \\
\text { score } 3 \text { month } \\
75.00 \pm 9.70\end{array}$} \\
\hline & Placebo & $72.99 \pm 8.97$ & \\
\hline recognition & $400 \mathrm{mg}$ & $74.83 \pm 8.27$ & $81.10 \pm 6.36^{*}$ \\
\hline (\%accuracy) & $800 \mathrm{mg}$ & $74.83 \pm 13.39$ & $85.07 \pm 6.85^{* * * *}$ \\
\hline 2.Word & Placebo & $1242.56 \pm 217.14$ & $1241.26 \pm 201.04$ \\
\hline recognition & $400 \mathrm{mg}$ & $1226.06 \pm 161.82$ & $1092.20 \pm 94.84 * *$ \\
\hline reaction time (msec.) & $800 \mathrm{mg}$ & $1261.14 \pm 176.75$ & $1077.15 \pm 100.74 * *$ \\
\hline 3.Simple & Placebo & $619.05 \pm 222.35$ & $621.70 \pm 146.77$ \\
\hline reaction time & $400 \mathrm{mg}$ & $616.25 \pm 195.39$ & $583.00 \pm 160.06$ \\
\hline (msec.) & $800 \mathrm{mg}$ & $623.25 \pm 191.43$ & $568.35 \pm 59.91$ \\
\hline 4.Digit vigilance & Placebo & $43.35 \pm 6.84$ & $43.75 \pm 6.47$ \\
\hline \multirow[t]{2}{*}{ (\%accuracy) } & $400 \mathrm{mg}$ & $42.90 \pm 5.05$ & $43.55 \pm 4.97$ \\
\hline & $800 \mathrm{mg}$ & $44.75 \pm 5.63$ & $50.35 \pm 5.62 * * *$ \\
\hline 5.Digit Vigilance & Placebo & $631.65 \pm 140.92$ & $627.20 \pm 109.61$ \\
\hline reaction time & $400 \mathrm{mg}$ & $620.00 \pm 122.74$ & $546.95 \pm 39.74 * *$ \\
\hline (msec.) & $800 \mathrm{mg}$ & $623.75 \pm 109.55$ & $516.00 \pm 69.15 * * *$ \\
\hline \multirow{4}{*}{$\begin{array}{l}\text { 6.Digit vigilance } \\
\text { false alarma number }\end{array}$} & & & \\
\hline & Placebo & $8.85 \pm 2.39$ & $8.2 \pm 1.39$ \\
\hline & $400 \mathrm{mg}$ & $8.85 \pm 2.18$ & $7.05 \pm 1.43 * *$ \\
\hline & $800 \mathrm{mg}$ & $8.65 \pm 2.13$ & $6.75 \pm 1.29 * * *$ \\
\hline 7.Choice reaction & Placebo & $79.90 \pm 7.40$ & $80.45 \pm 7.18$ \\
\hline time & $400 \mathrm{mg}$ & $80.00 \pm 8.86$ & $88.15 \pm 8.17 * *$ \\
\hline (\%accuracy) & $800 \mathrm{mg}$ & $79.05 \pm 8.53$ & $91.25 \pm 10.25^{* * *}$ \\
\hline 8.Choice reaction & Placebo & $976.00 \pm 168.70$ & $967.45 \pm 108.52$ \\
\hline time response & $400 \mathrm{mg}$ & $964.55 \pm 191.10$ & $880.95 \pm 100.66^{* * *}$ \\
\hline (msec.) & $800 \mathrm{mg}$ & $980.35 \pm 197.24$ & $860.65 \pm 108.11 * *$ \\
\hline 9.Numeric & Placebo & $73.90 \pm 10.40$ & $75.95 \pm 10.73$ \\
\hline working memory & $400 \mathrm{mg}$ & $75.50 \pm 8.67$ & $83.95 \pm 9.19 * *$ \\
\hline (\%accuracy) & $800 \mathrm{mg}$ & $76.45 \pm 9.69$ & $84.90 \pm 5.66 * *$ \\
\hline 10.Numeric & Placebo & $1334.50 \pm 226.25$ & $1322.60 \pm 171.31$ \\
\hline working memory & $400 \mathrm{mg}$ & $1339.40 \pm 234.61$ & $1310.70 \pm 174.98$ \\
\hline reaction time (msec.) & $800 \mathrm{mg}$ & $1335.60 \pm 260.95$ & $1305.65 \pm 214.19$ \\
\hline 11.Picture & Placebo & $72.99 \pm 8.97$ & $75.00 \pm 9.71$ \\
\hline recognition & $400 \mathrm{mg}$ & $74.83 \pm 8.27$ & $81.10 \pm 6.37$ \\
\hline (\%accuracy) & $800 \mathrm{mg}$ & $74.83 \pm 13.39$ & $85.07 \pm 6.86^{* * *}$ \\
\hline 12.Picture & Placebo & $1256.88 \pm 239.51$ & $1241.26 \pm 201.04$ \\
\hline recognition & $400 \mathrm{mg}$ & $1224.88 \pm 185.08$ & $1092.20 \pm 94.84$ \\
\hline reaction time(msec.) & $800 \mathrm{mg}$ & $1234.61 \pm 197.52$ & $1077.15 \pm 100.74 * *$ \\
\hline 13.Spatial & Placebo & $66.25 \pm 6.64$ & $67.10 \pm 4.62$ \\
\hline working memory & $400 \mathrm{mg}$ & $66.11 \pm 5.47$ & $70.73 \pm 4.37 * *$ \\
\hline (\%accuracy) & $800 \mathrm{mg}$ & $66.33 \pm 6.88$ & $71.90 \pm 3.51 * * *$ \\
\hline 14. Spatial & Placebo & $1799.25 \pm 33.45$ & $1821.30 \pm 289.87$ \\
\hline working memory & $400 \mathrm{mg}$ & $1784.30 \pm 191.92$ & $1695.65 \pm 255.55$ \\
\hline reaction time(msec.) & $800 \mathrm{mg}$ & $1712.75 \pm 219.45$ & $1467.85 \pm 197.52 * * *$ \\
\hline
\end{tabular}

Subjects were measured power of attention, continuity of attention, speed of memory and quality of memory by using computerized battery test. Data are presented as mean \pm SD ( $n=20$ /group). *, **, $* * *=\mathrm{P}$-value $<0.05,0.01$ and 0.001 compare to placebo treated group respectively

The current data also showed that subjects who received Zingiber officinale at dose of $800 \mathrm{mg}$ significantly decreased the latencies of both $\mathrm{N} 100(\mathrm{t}=$ 3.3936, $\mathrm{p}=0.0008)$ and $\mathrm{P} 300(\mathrm{t}=3.7677, \mathrm{p}=0.0003)$ compared to placebo treated group. However, the participants who obtained Zingiber officinale at dose of $400 \mathrm{mg}$ showed the significant change only in P300 latency $(\mathrm{t}=2.3654, \mathrm{p}=0.0116)$ compared to placebo treated group while no significant reduction of N100 latency was observed.

\section{Effect of Zingiber officinale on working memory}

Prior to the determination of Zingiber officinale on working memory, baseline data and mean pre-dose raw baseline scores for all three conditions (placebo, 400 and $800 \mathrm{mg}$ Zingiber officinale ) for each individual task scores were subjected to a one-way ANOVA. No significant changes of all parameters were observed.

Mean raw baseline scores and changes from baseline scores for each condition across each session are presented in the Table 3. It was found that at 3 months, subjects who consumed Zingiber officinale at dose of $400 \mathrm{mg} /$ day decreased the reaction time of word recognition time $(\mathrm{t}=2.9989, \mathrm{p}=0.0024)$, digit vigilance test $(\mathrm{t}=3.0781, \mathrm{p}=0.0019)$ and choice reaction time $(\mathrm{t}=2.6134, \mathrm{p}=0.0064)$ and increased \%accuracy of word recognition $(\mathrm{t}=2.3483, \mathrm{p}=0.0121)$, choice reaction $(\mathrm{t}=3.1633, \mathrm{p}=0.0015)$, numeric working memory $(\mathrm{t}=2.5332, \mathrm{p}=0.0078)$ and spatial working memory $(\mathrm{t}=2.5505, \mathrm{p}=0.0075)$. The subjects who had consumed the plant extract at dose of $800 \mathrm{mg} /$ day significantly increased \%accuracy of word recognition $(\mathrm{t}=3.7911, \mathrm{p}=0.0003)$, digit vigilance $(\mathrm{t}=3.4431, \mathrm{p}=$ $0.0007)$, choice reaction time $(\mathrm{t}=3.8575, \mathrm{p}=0.0002)$, numeric working memory $(\mathrm{t}=3.3002, \mathrm{p}=0.0011)$, picture recognition $(\mathrm{t}=3.4512, \mathrm{p}=0.0007)$ and spatial working memory $(\mathrm{t}=3.6946, \mathrm{p}=0.0003)$ and decreased the reaction times of numerous parameters including word recognition $(\mathrm{t}=3.2638, \mathrm{p}=0.0012)$, digit vigilance $(\mathrm{t}=3.8371, \mathrm{p}=0.0002)$, choice reaction time $(\mathrm{t}=3.1178, \mathrm{p}=0.0017)$, picture recognition $(\mathrm{t}=$ $2.8422, \mathrm{p}=0.0036)$ and spatial working memory $(\mathrm{t}=$ $3.9179, \mathrm{p}=0.0002)$. Therefore, our data suggested that the plant extract at doses used in this study significantly improved the following parameters (1) power of attention indicating by the decreased reaction times of simple reaction time, choice reaction time and digit vigilance tests, (2) the continuity of attention or accuracy of attention reflecting by the elevation of \%accuracy of the parameters mentioned above (3) the speed of memory which indicated by the reduction of reaction time of another parameters mentioned the computerized battery test used in this study (4) quality of memory indicating by the \%accuracy of the same parameters as mentioned in 3).

\section{DISCUSSION}

Our data clearly demonstrated the cognitive enhancing effect of ginger extract in the postmenopausal women. The consumption of ginger rhizome extract for 3 months significantly enhanced both attention and working memory.

Presently, it is well established that the components of Event Related Potential (ERP) were sensitive to attention and working memory demand of task (Gevins et al., 1996; McEvoy et al., 1998). It was reported that a large positive voltage deflection in an 
interval between $300-500 \mathrm{~ms}$ following stimulus onset which known as P3 or P300 (Picton, 1992) was corresponding to mental process such as recognition, categorization of stimuli and expectancy or short-term memory. The amplitude of this wave was correlated with individual differences in working memory capacity (Nittono et al., 1999) while its latency was regarded as a measurement of relative timing of the stimulus evaluation process which in turn indicated stimulus evaluating time (Rugg and Coles, 1995). In addition, it was also reported that N100 latency reflected process of activation of attention, analysis of information on physical characteristics of the sound while its amplitude was associated with the enhanced memory performance (Parageorgiou et al., 2009) such as attention (Picton and Hillyard, 1974), expectancy (Starr et al., 1997) and tasks involving short-term memory (Kaufman et al., 1992).

In addition to the event related potential, reaction time and \%accuracy of numerous psychological tests were also used as validated tools for assessing attention and memory. It was reported that power of attention could be evaluated using reaction time in choice reaction time and digit vigilance tests while continuity of attention was also able to be evaluated by using the $\%$ accuracy tests mentioned earlier. Moreover, speed and quality of memory were also evaluated by using reaction time and \%accuracy of numeric working memory, spatial memory and word and picture recognition (Kennedy et al., 2007). It was reported that lateral prefrontal cortex and monoamine system especially dopamine and norepinephrine played an important role on the numeric, word and picture recognition memory (D'Esposito et al., 1999; Smith and Jonides, 1999) while acetylcholine and serotonin in hippocampus simultaneously activated during performing spatial working memory (Moser and Moser, 1998; Stancampiano et al., 1999).

Previous studies also demonstrated that ginger or Zingiber officinale could enhance the level of norepinephrine, epinephrine, dopamine and serotonin contents in cerebral cortex and hippocampus (Waggas, 2009), the areas contributing the important role on working memory (D'Esposito et al., 1999; Smith and Jonides, 1999; Moser and Moser, 1998; Stancampiano et al., 1999). It also enhanced the memory performance induced by cerebral ischemia by decreasing infarct volume in both cortical and subcortical area (Watthanatorn et al., 2011). Furthermore, it could suppress AChE activity (Oboh et al., 2010). Therefore, taken all together, we suggest that the cognitive enhancing effect of Zingiber officinale might be partly associated with the modulation effect of this plant extract on the alteration of both monoamine system and the cholinergic system in cerebral cortex and hippocampus. However, the precise underlying mechanism is still required for further investigation.

\section{CONCLUSION}

In conclusion, the present study demonstrates that Zingiber officinale extract is the potential candidate cognitive enhancer for post-menopausal women. However, the precise underlying mechanism and the possible active ingredient further investigations are still required.

\section{ACKNOWLEDGEMENT}

This study was supported by The Integrative Complimentary Alternative Medicine Research Group and Graduate School, Khon Kaen University, Thailand Institute of Scientific and Technological Research, Pathumthani.

\section{REFERENCES}

Anderson, G.L., H.L. Judd, A.M. Kaunitz, D.H. Barad and S.A. Beresford et al., 2003. Effects of estrogen plus progestin on gynecologic cancers and associated diagnostic procedures: The Women's Health Initiative randomized trial. JAMA, 290: 1739-1748. DOI: 10.1001/jama.290.13.1739

Beral, V., 2003. Breast cancer and hormonereplacement therapy in the million women study. Lancet, 362: 419-427. DOI: 10.1016/S01406736(03)14592-8 PMID: 12927427

Beral, V., D. Bull, J. Green and G. Reeves, 2007. Ovarian cancer and hormone replacement therapy in the million women study. Lancet, 369: 1703-1710. DOI: $\quad 10.1016 / \mathrm{S} 0140-6736(07) 60534-0 \quad$ PMID: 17512855

Borrelli, F. and E. Ernst, 2010. Alternative and complementary therapies for the menopause. Maturitas, 66: 333-343. DOI: 10.1016/j.maturitas.2010.05.010 PMID: 20580501

Calle, E.E., H.S. Feigelson, J.S. Hildebrand, L.R. Teras and M.J. Thun et al., 2009. Postmenopausal hormone use and breast cancer associations differ by hormone regimen and histologic subtype. Cancer, 115: 936-945. DOI: 10.1002/cncr.24101 PMID: 19156895

D'Esposito, M., B.R. Postle, D. Ballard and J. Lease, 1999. Maintenance versus manipulation of information held in working memory: An eventrelated fMRI study. Brain Cogn., 41: 66-86. DOI: 10.1006/brcg.1999.1096 
Daniel, J.M. and J. Bohacek, 2010. The critical period hypothesis of estrogen effects on cognition: Insights from basic research. Biochim. Biophys. Acta, 1800: 1068-1076. DOI: 10.1016/j.bbagen.2010.01.007

Drake, M.E., A. Pakalnis and H. Padamadan, 1989. Long-latency auditory event related potentials in migraine. Headache, 29: 239-241. PMID: 2714975

Gevins, A., M.E. Smith, J. Le, H. Leong and J. Bennett et al., 1996. High resolution evoked potential imaging of the cortical dynamics of human working memory. Electroencephalogr Clin. Neurophysiol., 98: 327-348. DOI: 10.1016/00134694(96)00288-X

Greendale, G.A., R.G. Wight, M.H. Huang, N. Avis and E.B. Gold et al., 2010. Menopause-associated symptoms and cognitive performance: Results from the study of women's health across the nation. Am. J. Epidemiol., 171: 1214-1224. DOI: 10.1093/aje/kwq067

Halbreich, U., L.A. Lumley, S. Palter, C. Manning and F. Gengo et al., 1995. Possible acceleration of age effects on cognition following menopause. J. Psychiatr. Res., 29: 153-163. DOI: 10.1016/00223956(95)00005-P

Hildebrand, J.S., S.M. Gapstur, H.S. Feigelson, L.R. Teras and M.J. Thun et al., 2010. Postmenopausal hormone use and incident ovarian cancer: Associations differ by regimen. Int. J. Cancer, 127: 2928-2935. DOI: 10.1002/ijc.25515 PMID: 20560136

Kaufman, L., S. Curtis, J.Z. Wang and S.J. Williamson, 1992. Changes in cortical activity when subjects scan memory for tones. Electroencephalogr. Clin. Neurophysiol., 82: 266-284. DOI: 10.1016/00134694(92)90107-S PMID: 1372548

Keith, S., 2006. Ginger. In: Medicinal Seasoning. Medspice CC, Cape Town. pp: 93-94.

Kennedy, D.O., A.B. Scholey, L. Drewery, V.R. Marsh and B. Moore et al., 2003. Electroencephalograph effects of single doses of Ginkgo biloba and Panax ginseng in healthy young volunteers. Pharmacol. Biochem. Behav., 75: 701-709. DOI: 10.1016/S0091-3057(03)00120-5

Kennedy, D.O., P.A. Jackson, C.F. Haskell and A.B. Scholey, 2007. Modulation of cognitive performance following single doses of $120 \mathrm{mg}$ Ginkgo biloba extract administered to healthy young volunteers. Hum. Psychopharmacol. Clin. Exp., 22: 559-566. DOI: 10.1002/hup.885 PMID: 17902186

Keppel, G. and T.D. Wickens, 2004. Design and Analysis: A Researcher's Handbook. 4th Edn.,
Pearson Prentice Hall, New Jersey, ISBN: 9780135159415, pp: 611.

Khoo, S.K., S. O’Neill, G. Byrne, R. King and C. Travers et al., 2010. Postmenopausal hormone therapy and cognition: Effects of timing and treatment type. Climacteric, 13: 259-264. DOI: 10.3109/13697130903370316 PMID: 19886816

Kronenberg, F. and A. Fugh-Berman, 2002. Complementary and alternative medicine for menopausal symptoms: A review of randomized, controlled trials. Ann. Intern. Med., 137: 805-813. PMID: 12435217

Langner, E., S. Greifenberg and J. Gruenwald, 1998. Ginger: History and use. Adv. Ther., 15: 25-44. PMID: 10178636

Low, D.T., 2005. Menopause: A review of botanical dietary supplements. Am. J. Med., 118: 98-108. PMID: 16414334

McEvoy, L.K., M.E. Smith and A. Gevins, 1998. Dynamic cortical networks of verbal and spatial working memory: Effects of memory load and task practice. Cereb. Cortex, 8: 563-574. DOI: 10.1093/cercor/8.7.563

Moser, M.B. and E.I. Moser, 1998. Functional differentiation in the hippocampus. Hippocampus, 8: 608-619. PMID: 9882018

Moss, M.C., A.B. Scholey and K. Wesnes, 1998. Oxygen administration selectively enhances cognitive performance in healthy young adults: A placebo-controlled double-blind crossover study. Psychopharmacology (Berl), 138: 27-33. DOI: 10.1007/s002130050641 PMID: 9694523

Nittono, H., Y. Nageishi, Y. Nakajima and P. Ullsperger, 1999. Event-related potential correlates of individual differences in working memory capacity. Psychophysiology, 36: 745-754. DOI: 10.1111/1469-8986.3660745 PMID: 10554588

Oboh, G., A.O. Ademiluyi, A.J. Akinyemi, 2010. Inhibition of Acetylcholinesterase Activities and Some Pro-oxidant Induced Lipid Peroxidation in rat Brain by two Varieties of Ginger (Zingiber officinale). Exp. Toxicol. Pathol. DOI: 10.1016/j.etp.2010.09.004 PMID: 20952170

Parageorgiou, C., G.A. Giannakakis, K.S. Nikita, D. Anagnostopoulos and G.N. Papadimitriou et al., 2009. Abnormal auditory ERP N100 in children with dyslexia: Comparison with their control siblings. Behav. Brain Funct., 5: 26-26. DOI: 10.1186/1744-9081-5-26

Perfect, T.J. and E.A. Maylor, 2000. Models of Cognitive Aging. 1st Edn., Oxford University Press, New York, ISBN: 0198524382, pp: 310. 
Picton, T.W. and S.A. Hillyard, 1974. Human auditory evoked potentials. II. Effects of attention. Electroencephalogr. Clin. Neurophysiol., 36: 191199. DOI: 10.1016/0013-4694(74)90156-4 PMID: 4129631

Picton, T.W., 1992. The P300 wave of the human event-related potential. J. Clin. Neurophysiol., 9: 456-479. PMID: 1464675

Rocca, W.A., B.R. Grossardt and L.T. Shuster, 2010. Oophorectomy, menopause, estrogen and cognitive aging: The timing hypothesis. Neurodegener. Dis., 7: 163-166. DOI: 10.1159/000289229

Rugg, M.D. and M.G.H. Coles, 1995. Electrophysiology of Mind: Event-Related Brain Potentials and Cognition. 1st Edn., Oxford University Press, New York, ISBN: 0198521359, pp: 220 .

Schaafsma, M., J. Homewood and A. Taylor, 2010. Subjective cognitive complaints at menopause associated with declines in performance of verbal memory and attentional processes. Climacteric, 13: 84-98. PMID: 19722118

Sherwin, B.B., 2005. Estrogen and memory in women: How can we reconcile the findings? Horm. Behav., 47: 371-375. DOI: 10.1016/j.yhbeh.2004.12.002

Smith, E.E. and J. Jonides, 1999. Storage and executive processes in the frontal lobes. Science, 283: 16571661. PMID: 10073923

Srivastava, K.C. and T. Mustafa, 1992. Ginger (Zingiber officinale) in rheumatism and musculoskeletal disorders. Med. Hypotheses, 39: 342-348. DOI: 10.1016/0306-9877(92)90059-L

Stancampiano, R., S. Cocco, C. Cugusi, L. Sarais and F. Fadda, 1999. Serotonin and acetylcholine release response in the rat hippocampus during a spatial memory task. Neuroscience, 89: 1135-1143. DOI: 10.1016/S0306-4522(98)00397-2 PMID: 10362301

Starr, A., T. Aguinaldo, M. Roe and H.J. Michalewski, 1997. Sequential changes of auditory processing during target detection: Motor responding versus mental counting. Electroencephalogr. Clin. Neurophysiol., 105: 201-212. DOI: 10.1016/S0924-980X(97)00016-7 PMID: 9216489
Tong-Un, T., S. Muchimapura, W. Phachonpai and J. Wattanathorn, 2010. Effects of quercetin encapsulated liposomes via nasal administration: A novel cognitive enhancer. Am. J. Applied Sci., 7: 906-913. DOI: 10.3844/ajassp.2010.906.913

Verma, S.K. and A. Bordia, 2001. Ginger, fat and fibrinolysis. Indian J. Med. Sci., 55: 83-86. PMID: 11482162

Waggas, A.M., 2009. Neuroprotective evaluation of extract of ginger (Zingiber officinale) root in monosodium glutamate-induced toxicity in different brain areas male albino rats. Pak. J. Biol. Sci., 12: 201-212. PMID: 19579948

Wattanathorn, J., L. Mator, S. Muchimapura, T. Tongun and O. Pasuriwong et al., 2008a. Positive modulation of cognition and mood in the healthy elderly volunteer following the administration of Centella asiatica. J. Ethnopharmacol., 116: 325332. DOI: 10.1016/j.jep.2007.11.038 PMID: 18191355

Wattanathorn, J., P. Chonpathompikunlert, S. Muchimapura, A. Priprem and O. Tankamnerdthai, 2008b. Piperine, the potential functional food for mood and cognitive disorders. Food Chem. Toxicol., 46: 3106-3110. DOI: 10.1016/j.fct.2008.06.014 PMID: 18639606

Watthanatorn, J., J. Jittiwat, T. Tongun, S. Muchimapura and K. Ingkaninan, 2011. Zingiber officinale mitigates brain damage and improves memory impairment in focal cerebral ischemic rat. Evid. Based Complement Alternat. Med. DOI: 10.1155/2011/429505

Weber, M. and M. Mapstone, 2009. Memory complaints and memory performance in the menopausal transition. Menopause, 16: 1-7. PMID: 19276998

Wesnes, K.A., 2001. The use of cognitive tests to facilitate drug and dose selection in Phase I and to optimise dosing in Phase IV. Int. Cong. Series, 1220: 35-50. DOI: 10.1016/S0531-5131(01)002850 